\title{
A FAST HYSTERESIS CURRENT-CONTROLLED PERMANENT MAGNET SYNCHRONOUS MOTOR DRIVE BASED ON FIELD ORIENTATION
}

\author{
Cosmas Ogbuka - Cajethan Nwosu - Marcel Agu
}

\begin{abstract}
A fast hysteresis current-controlled (HCC) permanent magnet synchronous motor (PMSM) drive based on field orientation is presented. The objectives of this research are to develop and utilize HCC algorithm for field orientation control (FOC) of a complete closed loop speed-controlled PMSM drive system, optimize the HCC algorithm to obtain fast speed response with step and ramp speed inputs to examine the effectiveness of current and torque tracking, identify the optimal control variables of the HCC on the PMSM, examine the performance with ramp and step reference speed inputs. The response of the developed model is compared with the speed response of the standard AC6 of MATLAB Simpower systems in terms of rise time, settling time and effectiveness of current and torque tracking. Compared to the standard AC6 of MATLAB Simpower systems, the developed model achieved rise time and settling time of 0.0108 seconds and 0.0143 seconds respectively while the corresponding values for AC6 model are 0.1944 seconds and 0.1984 seconds respectively. The developed model, therefore, offered superior performance over the AC6 model in terms of rise time, settling time and tracking capability.
\end{abstract}

K e y w ord s: hysteresis current control, field orientation, PMSM, voltage source inverter

\section{INTRODUCTION}

For the same output power, Permanent Magnet Synchronous Motors (PMSM) offer performance enhancement over the conventional induction and synchronous motors in terms of power factor, efficiency, power density and torque-to-inertia ratio [1]. This justifies the recent concentration of research efforts in the design, analysis and control of the PMSM as reported in [2-7]. Recently, several efforts have been made toward the operational comparison between the permanent magnet synchronous motor and the induction motor which, hitherto, is the workhorse of the industry. These comparisons have favoured the PMSM both for fixed speed and variable speed operations $[8,9]$. Line-start PMSM has also been favourably compared with induction motors in the field of semi-hermetic drives, like in compressors, where heavy loading is obtained because of good cooling [10].

Permanent magnet materials are rated on the basis of energy density and resistance for demagnetization and this directly influences the performance of the PMSM. Neodymium Iron Boron $\left(\mathrm{Nd}_{2} \mathrm{Fe}_{14} \mathrm{~B}\right)$ magnets (second generation rare earth magnet) are the most common rare earth magnets used in PM motors these days because of their superior B-H characteristics. The rare-earth PMs have problems such as high cost and are in very limited supply. The unpredictability associated with procuring such materials, clearly, suggests the need for a competitive alternative. Several research efforts are on-going to utilize ferrite magnets in place of Permanent magnets where the ferrites are expected to have competitive power density and efficiency of the rare-earth PMSM [11-14].
Unlike in low precision applications where open loop fixed speed operation of the PMSM may be tolerated, Adjustable Speed Drives (ASD), depending on specific load requirements, significantly improves motor drive performance. This is the practice in industry where high precision in speed and torque is desired. Faster and accurate speed response, quicker recovery of speed from any load impact, and insensitivity of parameter variations are some of the important criteria of adjustable speed drive to achieve high performance for such applications like in robotics, rolling mills, air conditioners, air compressors, spindle drives, and other machine tools [15].

Since torque can be made proportional to current either in the stationary or rotor reference frames and control of current gives control of torque and speed, current control strategies are employed in ASD to ensure that stator phase currents track their respective reference values. One of such current control strategies is the Hysteresis Current Control (HCC). The HCC when compared to other current control strategies offers superior current tracking performance and eliminates the need for feedback loop compensation [16]. The problems of poor load transient response and regulator inaccuracy have, however, consistently necessitated further research efforts to achieve optimal drives performance [17-20].

In the present work, a fast hysteresis current controlled permanent magnet synchronous motor drive based on field orientation was developed and optimised to obtain fast speed response and effective current and torque tracking. Being a speed-controlled drive system, a comparison of the drive performance for step and ramp speed inputs was undertaken. The results obtained were then

\footnotetext{
* Department of Electrical Engineering, University of Nigeria, Nsukka, Nigeria. cosmas.ogbuka@unn.edu.ng, cajethan.nwosu@unn.edu.ng, marcel.agu@unn.edu.ng
} 


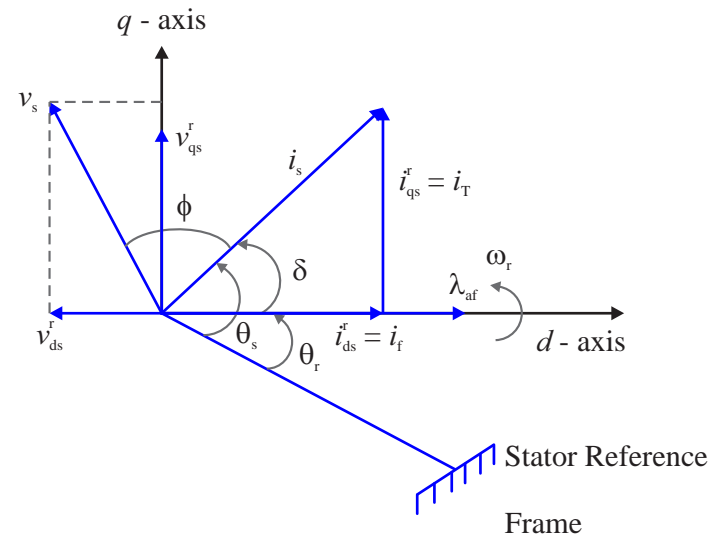

Fig. 1. Phasor diagram of vector control by FOC for PMSM

compared with the results of the standard AC6 of the Simpower of MATLAB and the developed model showed superior performance.

\section{DYNAMIC MODEL OF PMSM}

The stator of the PMSM and the wound rotor synchronous motor are similar. In addition there is no difference between the back emf produced by permanent magnet and that produced by an excited coil. Hence the mathematical model of a PMSM is similar to that of the wound rotor synchronous motor. The following simplifying assumptions were made to derive the dynamic model of the PMSM in the rotor reference frame. The machine has no damping circuits since it is inverter controlled and the effect of saturation and parameter variations are neglected $[1,21]$.

Based on these assumptions, the stator qd equations of the PMSM, in the rotor reference frame, is derived as

$$
\left[\begin{array}{c}
v_{q s}^{r} \\
v_{d s}^{r}
\end{array}\right]=\left[\begin{array}{cc}
R_{s}+L_{q} p & \omega_{r} L_{d} \\
-\omega_{r} L_{q} & R_{s}+L_{d} p
\end{array}\right]\left[\begin{array}{c}
i_{q s}^{r} \\
i_{d s}^{r}
\end{array}\right]+\left[\begin{array}{c}
\omega_{r} \lambda_{a f} \\
0
\end{array}\right]
$$

The electromagnetic torque is obtained as

$$
T_{e}=\frac{3}{2} \frac{P}{2}\left[\lambda_{a f}+\left(L_{d}-L_{q}\right) i_{d s}^{r}\right] i_{q s}^{r}
$$

The rotor dynamic equations are

$$
T_{e}=T_{L}+B \omega_{r}+J p \omega_{r}
$$

and

$$
\theta_{r}=\int \omega_{r} \mathrm{~d} t
$$

where $v_{q s}^{r}, v_{d s}^{r}=\mathrm{q}, \mathrm{d}$ axis voltage, $i_{q s}^{r}, i_{d s}^{r}=\mathrm{q}, \mathrm{d}$ axis currents, $L_{q}, L_{d}=$ q,d axis inductances, $R_{s}=$ stator resistances, $\lambda_{a f}=$ stator resistances, $\omega_{r}=$ angular rotor speed, $P=$ number of motor poles, $p=$ differential operator, $T_{e}=$ electromagnetic torque, $T_{L}=$ load torque, $B=$ rotor damping coefficient, $J=$ inertia constant.

\section{FIELD ORIENTATION CONTROL (FOC) OF PMSM}

Vector control, by field orientation, is used to decouple the stator current of the PMSM into equivalent flux and torque producing current components for independent and precise control of torque and flux like in DC machine as shown in the phasor diagram of Fig. 1.

As shown in Fig. 1, the rotor flux linkage revolves at a rotor speed $\omega_{r}$ and is positioned away from a stationary reference by the rotor angle $\theta_{r}$. The stator current phasor is at angle $\delta$ from the rotor flux linkages phasor. Field orientation control is achieved by making $\delta=90^{\circ}$ thereby rendering the stator flux current component zero.

$$
i_{f}=i_{d s}^{r}=i_{s} \cos \delta=0
$$

Therefore,

$$
T_{e}=\frac{3}{2} \frac{P}{2} \lambda_{a f} i_{q s}^{r}
$$

Since $\sin 90^{\circ}=1, i_{q s}^{r}=i_{s}$

$$
T_{e}=\frac{3}{2} \frac{P}{2} \lambda_{a f} i_{s}=K_{t} i_{s}
$$

where $K_{t}=\frac{3}{2} \frac{P}{2} \lambda_{a f}$ is the torque constant.

Under this condition, the PMSM behaves exactly as the separately excited dc motor [22] as seen from the torque expression (7) where the torque is produced by the interaction of the rotor flux and the stator current.

\section{SCHEMATIC OF THE SPEED-CONTROLLED DRIVE SYSTEM}

The complete Schematic of the Speed-Controlled PMSM Drive System is shown in Fig. 2. It consists of the PMSM, the Speed and Position Feedback, PI Speed Controller, Hysteresis Current Controller and the Three Phase Voltage Source Inverter.

All reference or command values are superscripted with $*$ in the drive diagram. The rotor speed sensed by the speed sensor is filtered by the 1st order low pass filter. The speed error between the actual rotor speed and its reference $\left(\omega_{r}^{*}-\omega_{r}\right)$ is processed through the PI speed controller to nullify the steady state error in speed. The output of the speed controller is the torque reference which is restricted to an upper and a lower limit by the torque limiter thereby producing a realistic torque reference $T_{e}^{*}$.

The torque reference $T_{e}^{*}$ is divided by the motor torque constant $K_{t}=\frac{3}{2} \frac{P}{2} \lambda_{a f}$ to produce the reference quadrature axis current $i_{q s}^{r *}$. To achieve vector control by field orientation, the reference direct axis current $i_{d s}^{r *}=0$. The $i_{d s}^{r *}$ and $i_{q s}^{r *}$ are passed through the inverse park's transform block to produce the stator abc phase current references $i_{a}^{*}, i_{b}^{*}$, and $i_{c}^{*}$. Electrical rotor position $\theta_{e}$ feedback realised by integrating the electrical rotor speed 


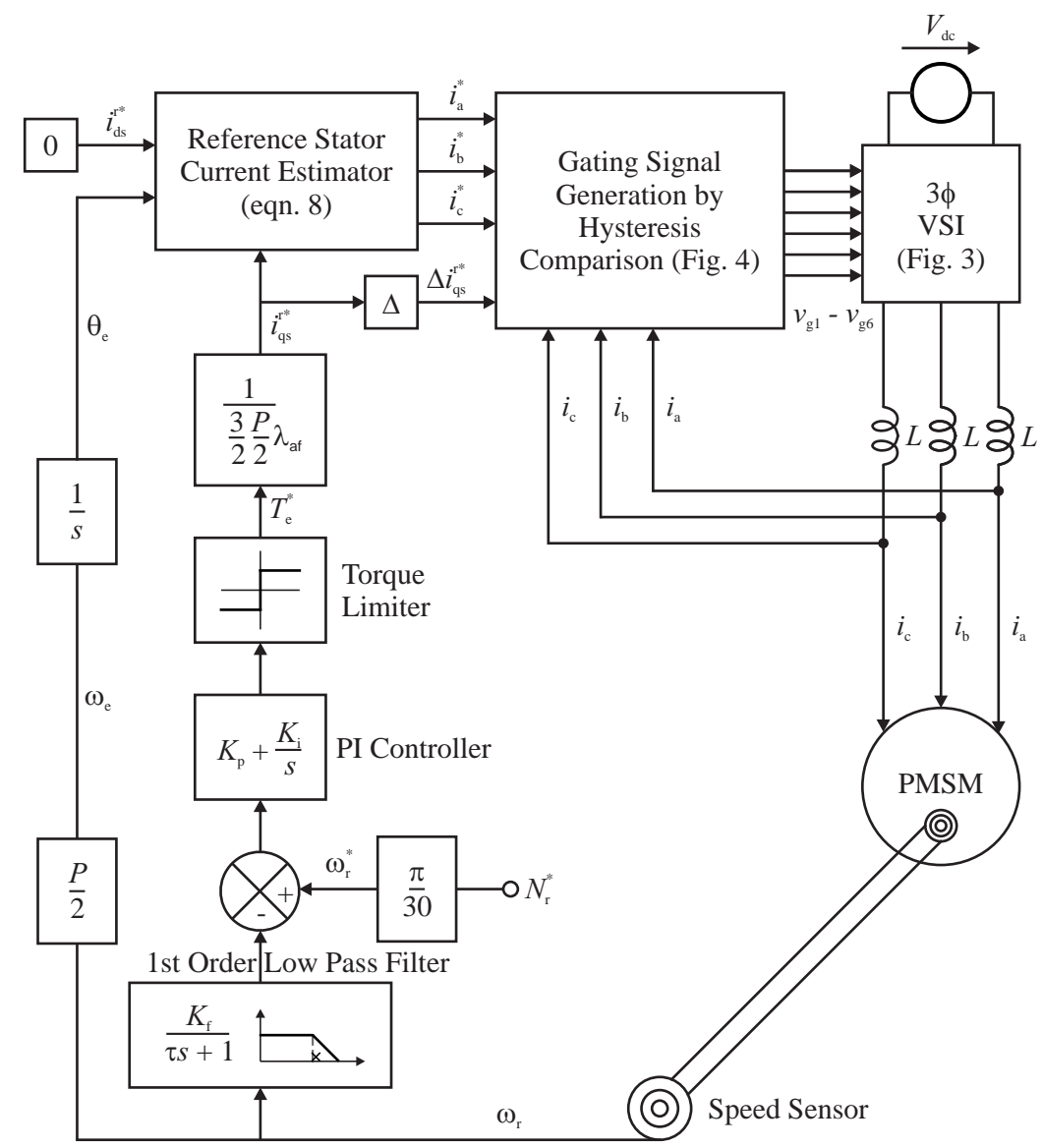

Fig. 2. Complete schematic of the speed-controlled PMSM drive system

$\omega_{e}$ is required in order to generate the phase current references as shown in

$$
\begin{aligned}
& i_{a}^{*}=i_{q s}^{r *} \cos \theta_{e}+i_{d s}^{r *} \sin \theta_{e}, \\
& i_{b}^{*}=i_{q s}^{r *} \cos \left(\theta_{e}-\frac{2 \pi}{3}\right)+i_{d s}^{r *} \sin \left(\theta_{e}-\frac{2 \pi}{3}\right), \\
& i_{c}^{*}=i_{q s}^{r *} \cos \left(\theta_{e}+\frac{2 \pi}{3}\right)+i_{d s}^{r *} \sin \left(\theta_{e}+\frac{2 \pi}{3}\right) .
\end{aligned}
$$

Since torque can be made proportional to current either in the stationary or rotor reference frames and control of current gives control of speed and position, control of PMSM drives is exercised through current control. To achieve high performance from servo drives, current control strategies are employed to ensure that the actual currents flowing into the motor are as close as possible to the sinusoidal references using Hysteresis Current Control (HCC). In this strategy, the reference phase currents $\left(i_{a}^{*}\right.$, $i_{b}^{*}$ and $\left.i_{c}^{*}\right)$ and the actual phase currents $\left(i_{a}, i_{b}\right.$ and $\left.i_{c}\right)$ are compared, by feedback, and error signals generated. At the centre of the variable speed drive of the PMSM, and in fact all ac drives, is the three phase inverter with the typical power circuit shown in Fig. 3. The power circuit consists of six self-commuted semiconductor switches $\mathrm{S}_{1}$ to $\mathrm{S}_{6}$ with their corresponding antiparallel diodes used to control the stator phase currents. The control logic of appendix one is employed to generate the gating signals $v_{g 1}, v_{g 2}, v_{g 3}, v_{g 4}, v_{g 5}, v_{g 6}$ for the switches of the three phase inverter of as shown in Fig. 4. Current control is achieved by the appropriate firing of the power semiconductor switches $\mathrm{S}_{1}$ to $\mathrm{S}_{6}$ of the three phase inverter. The inverter is supplied by an adequately filtered dc source $V_{d c}$. The phase currents to the motor is limited by inductor $L$ of $5 \mathrm{mH}$.

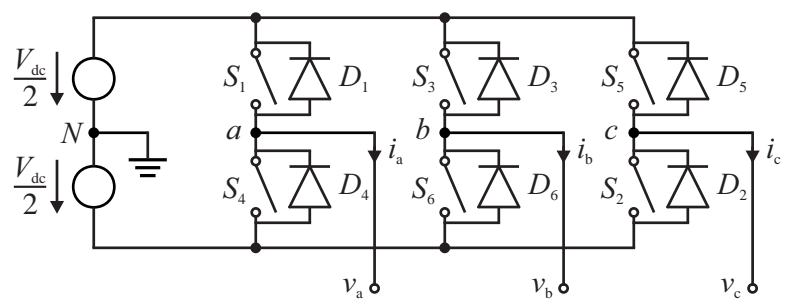

Fig. 3. Power circuit of three-phase inverter

The HCC action is made possible by using $\Delta i_{q s}^{r *}$ as shown in the Fig. 2 where $\Delta$, in the range of $0.02 \leq \Delta \leq$ 0.05 , is the hysteresis window. Similar logic applies to the other two phases.

\section{RESULTS AND DISCUSSIONS}

The complete drive system is simulated for the motor of appendix two and the results presented here for step and ramp reference speed inputs. To obtain the best 


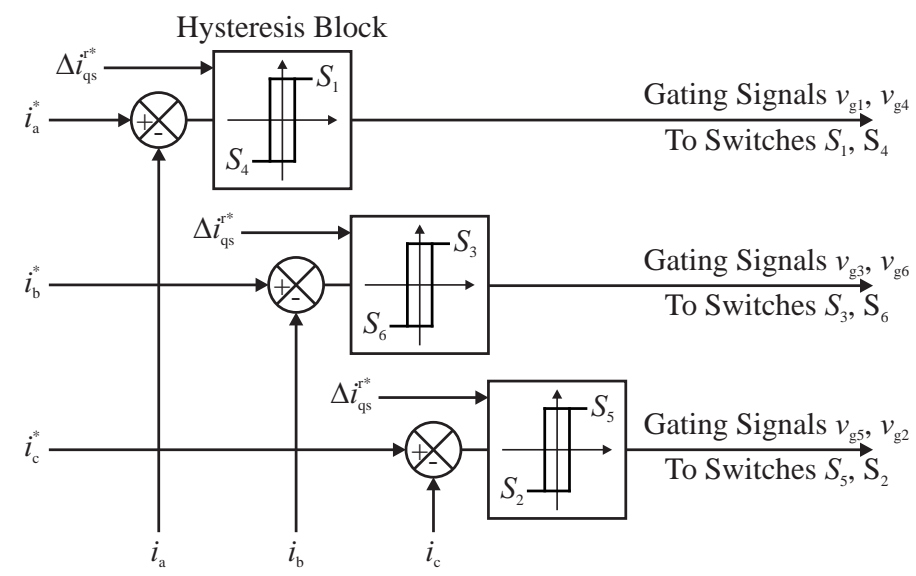

Fig. 4. Generating of gating signals for hysteresis current control

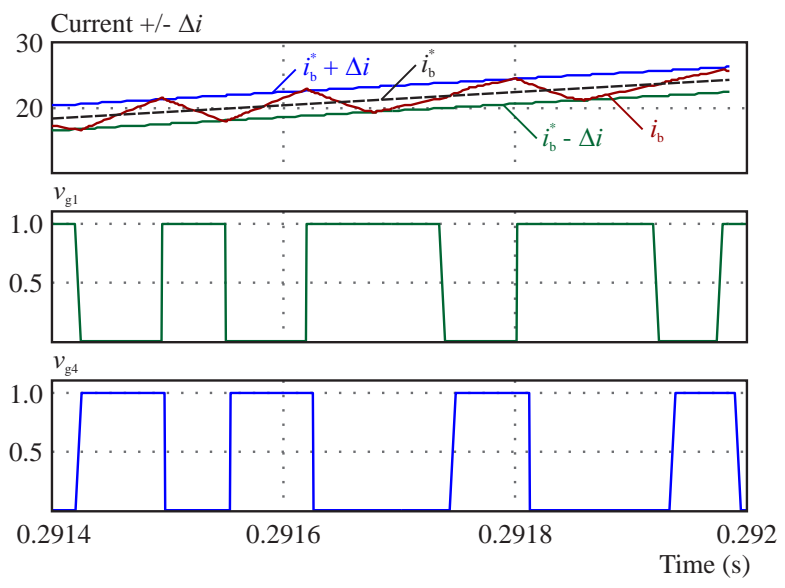

Fig. 5. Phase 'a' hysteresis current with $\mathrm{S} 1$ and $\mathrm{S} 4$ gating signal

possible performance, tuning method was employed to obtain the optimal proportional and integral gain values. The procedure is to lower the proportional and integral gain values and gradually tune them up until the best possible performance is achieved. This is the practice in industry. The optimal control variables are: proportional gain $=5$, integral gain $=100,1$ st order low pass filter time constant $=1.6 \times 10^{-3}$ seconds, torque limiter upper lower $=30 \mathrm{Nm} /-30 \mathrm{Nm}$, hysteresis band $\Delta=0.05$.

\subsection{Hysteresis Current Control Action}

The gating signals, vg1 and vg4, for the complementary switches in the first leg of the inverter S1 and S4 are shown in Fig. 5 using phase 'a' to highlight the hysteresis property for a narrow time band (0.2914 seconds to 0.292 seconds) for purpose of clarity. It can be seen that the two switches conduct alternately as earlier explained. The phase 'a' current $i_{a}$ tracts the upper boundary $i_{a}^{*}+\Delta i_{q s}^{r *}$ (increases) when switch $\mathrm{S} 1$ is conducting and tracts the lower boundary $i_{a}^{*}-\Delta i_{q s}^{r *}$ (decreases) when switch S4 is conducting. The hysteresis current control action, which makes the phase 'a' current $i_{a}$ to track its reference $i_{a}^{*}$,

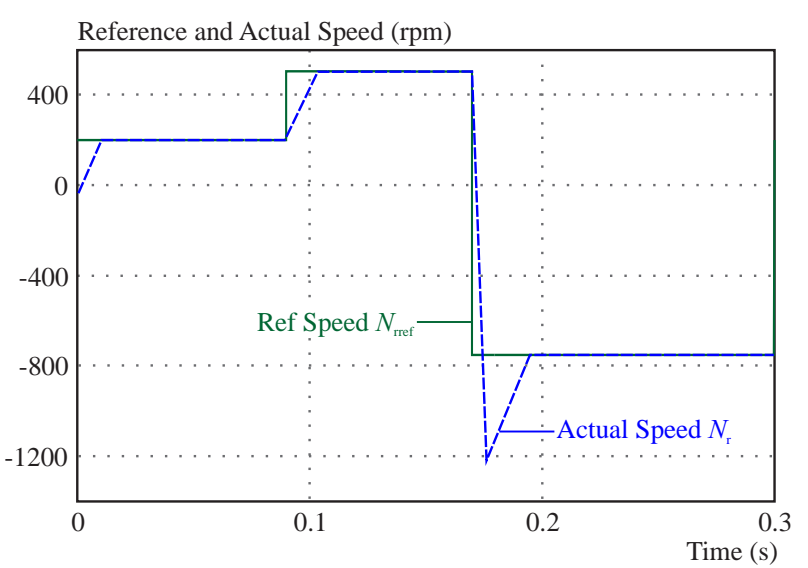

Fig. 6. Reference and actual rotor speed for step speed input

is seen as $i_{a}$ moves between $i_{a}^{*}+\Delta i_{q s}^{r *}$ to $i_{a}^{*}-\Delta i_{q s}^{r *}$ as switches S1 and S4 conduct alternately.

\subsection{Step Speed Input (200 rpm to 500rpm to -750rpm)}

The motor is started at a reference speed input of $200 \mathrm{rpm}$ at full load stress as shown in Fig. 6. At 0.09 seconds, the speed reference is stepped-up to $500 \mathrm{rpm}$. At 0.17 seconds, a negative speed command of $-750 \mathrm{rpm}$ is issued. It is observed that the rotor speed would, after brief transients, catch-up and remain at the reference speed in each case of speed change.

Figures 7(a),(b) show the reference phase currents and the actual phase currents. The phase currents responded to two step speed changes. A close observation shows that the switching frequency increased by $150 \%$ as reference speed is stepped from $200 \mathrm{rpm}$ to $500 \mathrm{rpm}$. A $50 \%$ increase in switching speed is also observed as speed changed from $500 \mathrm{rpm}$ to $-750 \mathrm{rpm}$. The actual phase current effectively tracks the reference.

Of specific interest is the nature of phase inversion (reversal) from a-b-c to c-b-a that occurs as speed changes from $500 \mathrm{rpm}$ to $-750 \mathrm{rpm}$. The expanded view is shown 

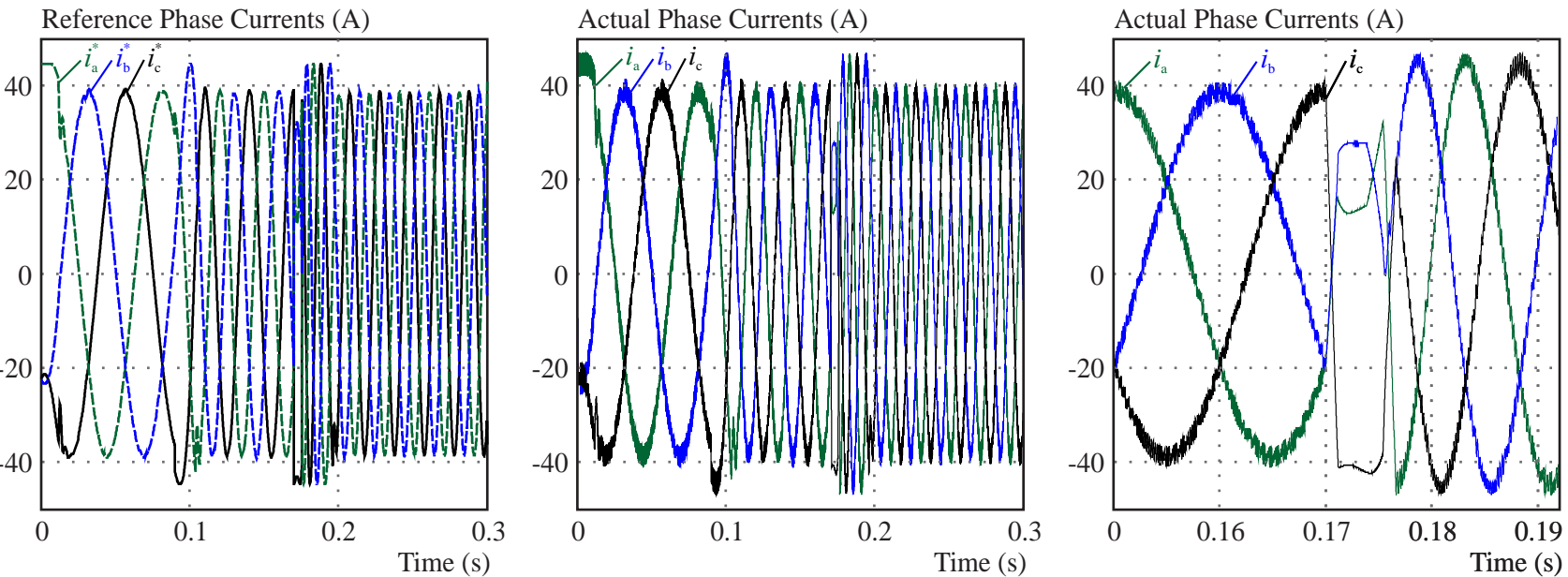

Fig. 7. Step input responses: (a)- phase currents, (b) - actual phase currents, (c) - current phase reversal (expanded)
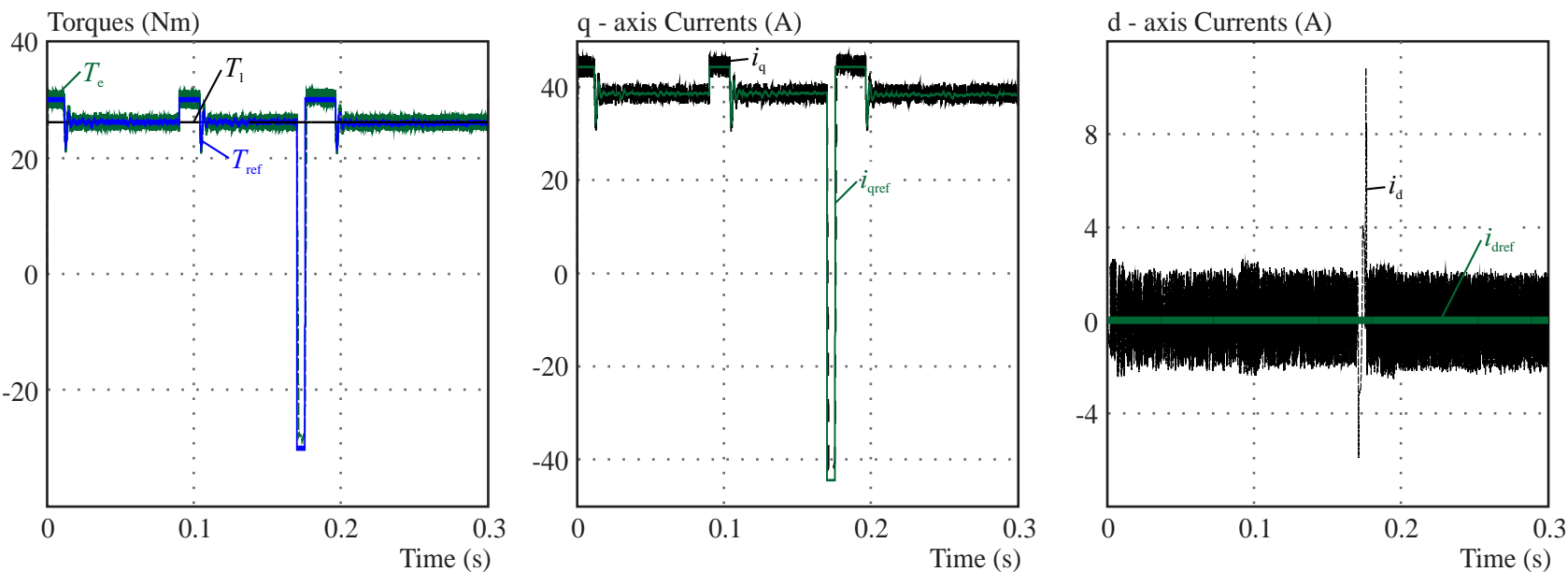

Fig. 8. Step-speed input responses: (a) - electromagnetic torque, reference torque and load torque for step speed input, (b) - q-axis stator current, actual $i_{q s}^{r}$ and reference $i_{q s}^{r *}$, and (c) - d-axis stator current, actual $i_{d s}^{r}$ and reference $i_{d s}^{r}$ and reference $i_{q s}^{r}$ and reference
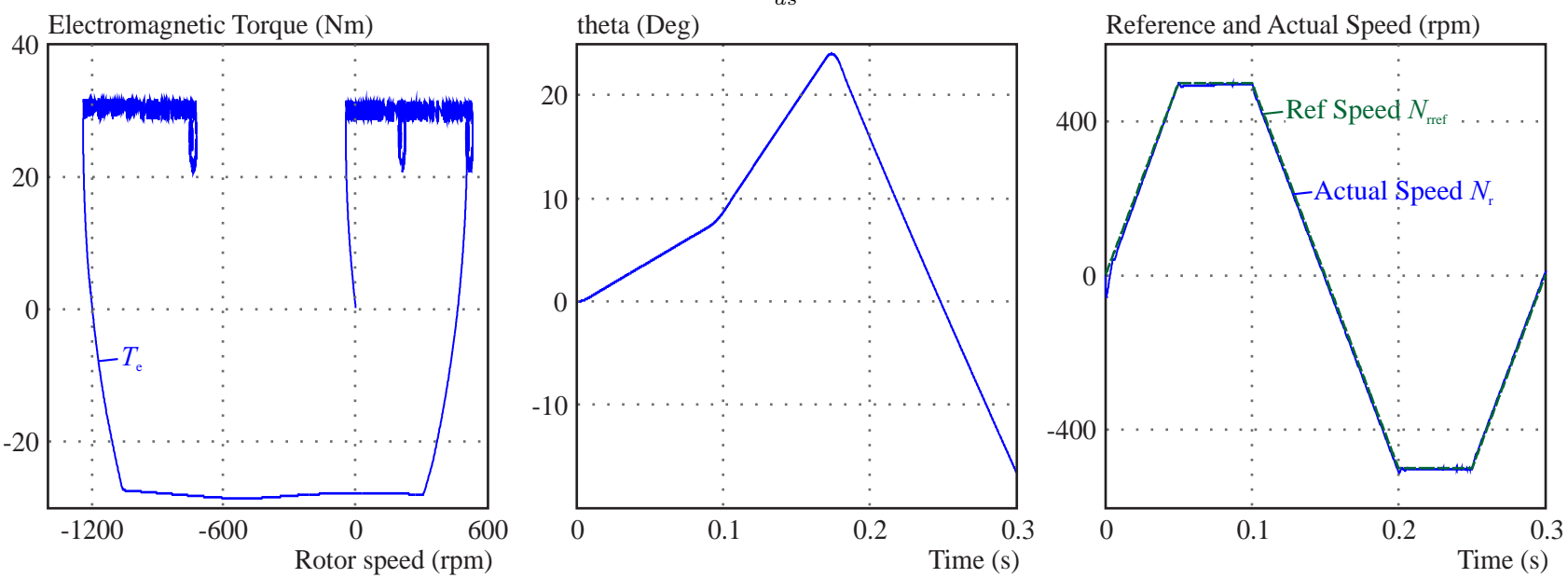

Fig. 9. Step-speed responses: (a) - torque-speed profile, (b) - rotor position $\theta_{r}$, (c) - reference and actual rotor speed at RAMP input

in Fig. 7(c). As shown in Fig. 8(a) during starting, reference torque and the electromagnetic torque equals the maximum set torque capability. This ensures that the rotor runs-up in the shortest possible time. As soon as the rotor speed catches-up with the reference, the electromag- netic torque and the torque reference settles at the load torque and the rotor cruises at $200 \mathrm{rpm}$.

At time 0.09 seconds when speed is stepped-up to $500 \mathrm{rpm}$, the reference torque again attains the maximum possible torque of $30 \mathrm{Nm}$. At the instant of step speed 

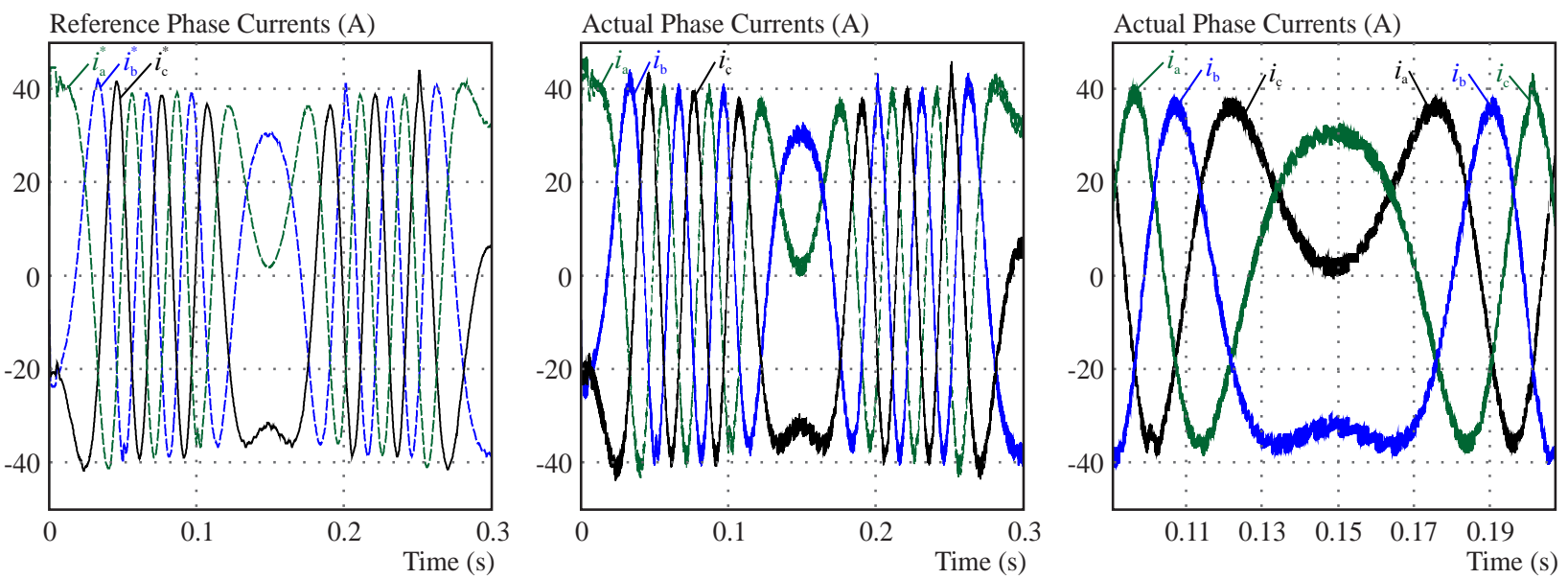

Fig. 10. RAMP-speed input response: (a) - reference phase currents, (b) - actual phase currents, and (c) - current phase reversal (expanded)
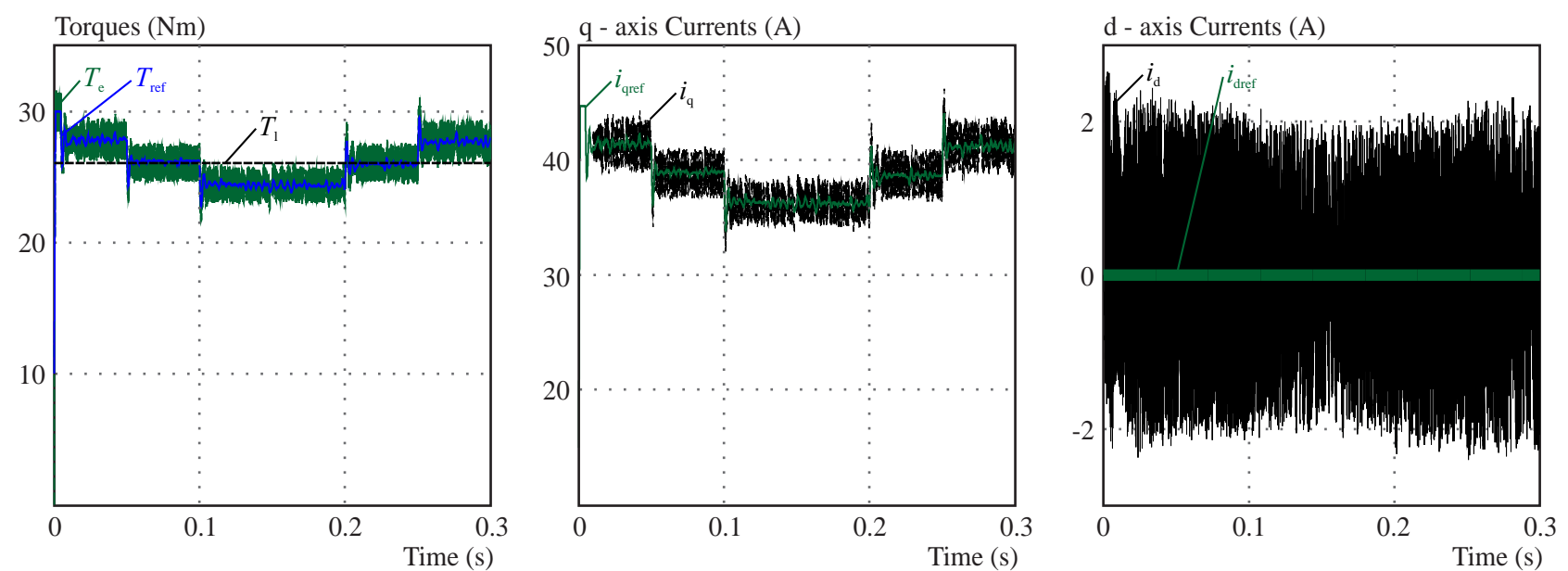

Fig. 11. RAMP-speed input response: (a) - electromagnetic torque $T_{e}$, reference torque $T_{r e f}$, and load torque $T_{l}$, (b) - q-axis stator current, actual $i_{q s}^{r}$ and reference $i_{q s}^{r *}$, and (c) - d-axis stator current, actual $i_{d s}^{r}$ and reference $i_{d s}^{r *}$
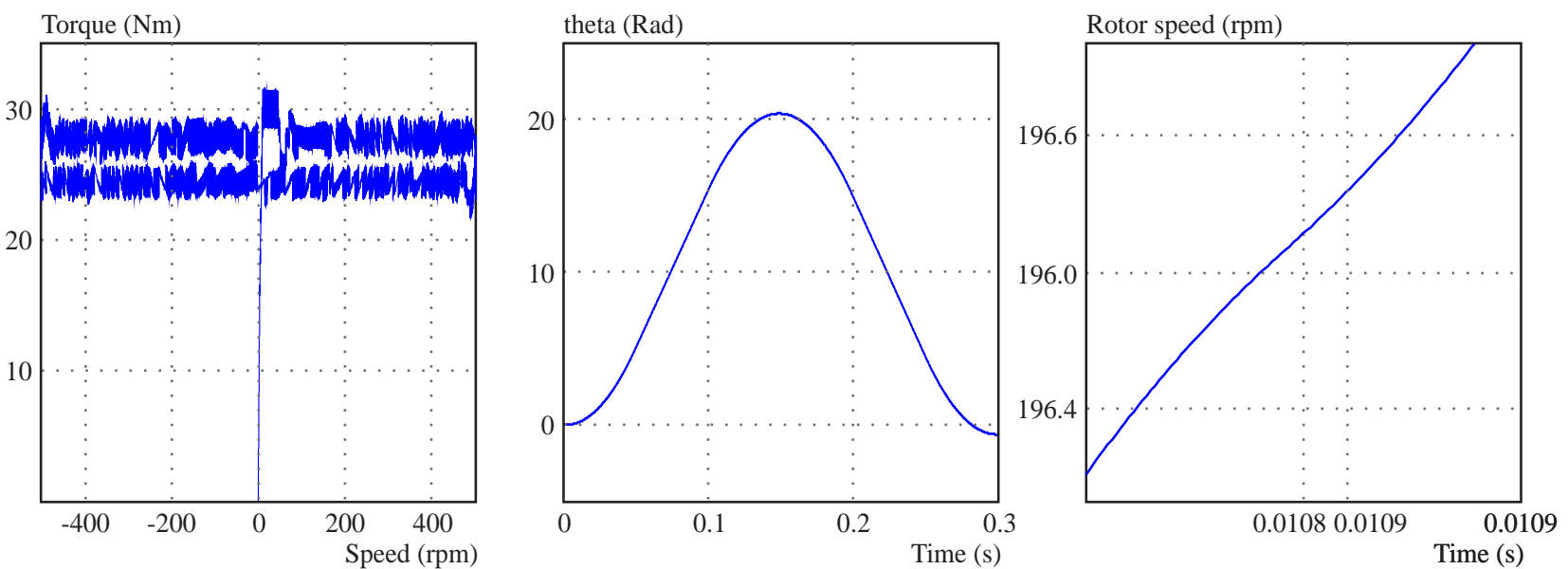

Fig. 12. RAMP-speed input response: (a) - torque-speed profile, (b) - rotor position $\theta_{r}$ - d-axis stator current, actual $i_{d s}^{r}$ and reference $i_{d s}^{r *}$, and (c) the rise time for the developed model

change from $500 \mathrm{rpm}$ to $-750 \mathrm{rpm}$ at 0.17 seconds, the reference torque attains the minimum value of $-30 \mathrm{Nm}$. As soon as stability is achieved after each case of speed change, the reference torque is restored to $26 \mathrm{Nm}$ which is the full load torque.
Since electromagnetic torque is directly proportional to the q-axis stator current, q-axis stator current shown in Fig. 8(b) has exactly the same response characteristics as the electromagnetic torque; with the actual value effectively tracking the reference. A deep transient due 

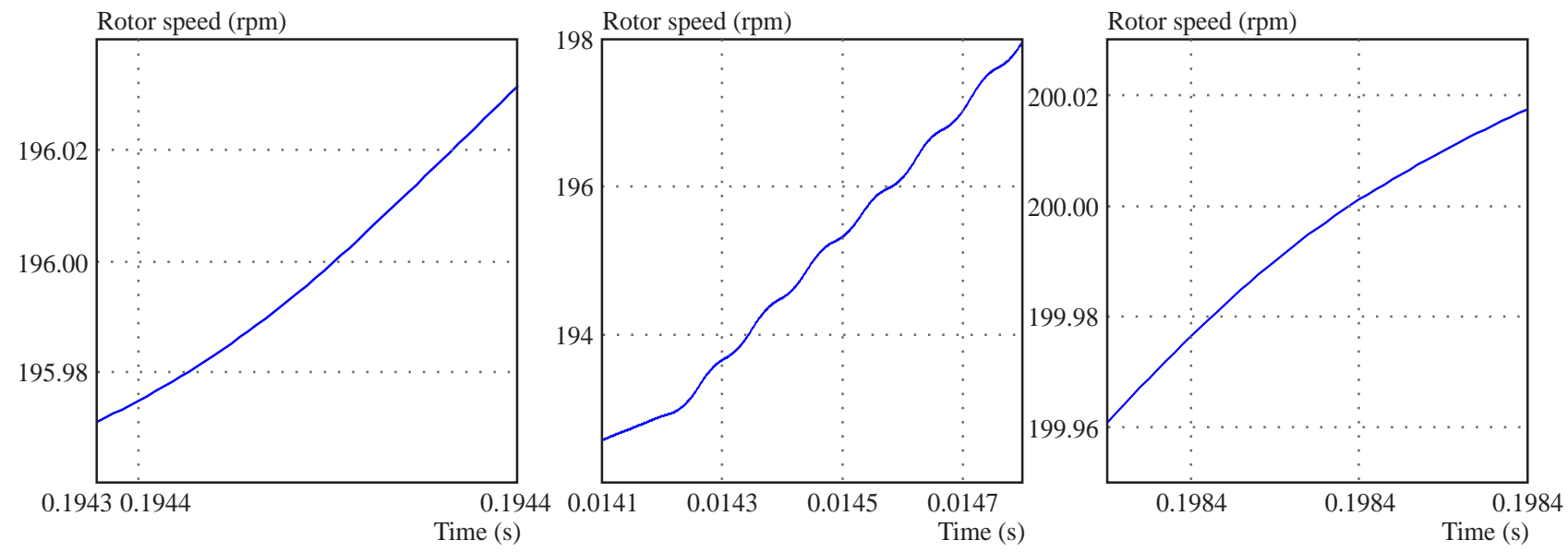

Fig. 13. (a) - the rise time - AC6 model, (b) - settle time for the developed model, and (c) - Settle time for the AC6 model

to speed reversal is observed in the d-axis stator current in Fig. 8(c). The reference value is set at zero while the actual value averages to zero.

Figure 9(a) shows the torque-speed profile in all four quadrants of operation namely: forward motoring, forward regeneration, reverse motoring, and reverse regeneration.

The rotor position is zero at start and increases for as long as speed remains positive but creates a new orientation with speed change. When reference speed is made negative, the rotor reverses direction as shown in Fig. 9(b).

\section{(c) RAMP Speed Input (0 rpm to $500 \mathrm{rpm}$ to $-500 \mathrm{rpm}$ to $0 \mathrm{rpm})$}

The reference speed input is a ramp; rising from zero to positive input value of $500 \mathrm{rpm}$ and falling back to negative input value of $-500 \mathrm{rpm}$ and then to zero. A combined plot of the reference speed input and actual rotor speed is shown in Fig. 9(c). As can be seen, ramping provides a gradual speed transition thereby enabling the actual rotor speed to trace the path of the reference speed input very closely.

Just as in the case of step speed input, phase sequence reversal also occur at the instant of speed change from positive to negative as seen in Figs. 10(a) and (b). A comparison of Fig. 7(c) and Fig. 10(c), however, shows that excellent dynamic stability is obtained during phase reversal in the case of ramp input. Ramp input provides smooth speed transition.

Unlike in the step input where the reference torque takes its minimum value at the instant of speed reversal thereby, momentarily, forcing the electromagnetic torque to the negative extreme, the torque-speed profile during speed ramping as shown in Fig. 12(a) is positive due to the gradual speed transition. Electromagnetic torque and its reference are equal to the load torque at steady state as shown in Fig. 11(a).

\section{DRIVE SPEED RESPONSE COMPARED WITH RESPONSE OF MATLAB SIMPOWER AC6 MODEL}

The speed response of the developed drive model is compared with the speed response of the AC6 of MATLAB Simpower Systems under the same condition of operation (Constant reference speed of $200 \mathrm{rpm}$ at no load). Emphasis was paid on the rise time and settling time of the speed response. While the developed model achieved rise time (ie $98 \%$ of final time) in 0.0108 seconds, the rise time for AC6 model is 0.1944 seconds. These are shown in Fig. 12(c) and 13(a) respectively.

With settling time defined, for an under damped system, as the time $t x$ it becomes $98 \%$ of final value or less for all $t \geq t x$, the settling time for the developed model is 0.01435 seconds. The response for AC6 is critically damped; hence the settling time coincides with the final value time which is 0.1984 seconds. These are shown in Fig. 13(b) and 13(c) respectively.

\section{CONCLUSION}

A fast hysteresis current controlled permanent magnet synchronous motor drive based on field orientation has been presented in this work. The specific research objectives have been achieved as shown in the results.

The core advantage of vector control by Field Orientation Control (FOC) has been used in this work to, successfully, convert the Permanent Magnet Synchronous Motor, performancewise, into equivalent separately excited dc motor by decoupling the stator current into torque and flux producing components for independent control of torque and flux.

A complete closed loop control system employing an outer PI speed controller and an inner hysteresis current controller was implemented to realize this speedcontrolled drive. Since torque can be made proportional to current either in the stationary or rotor reference 
frames and effective control of current gives effective control of torque, speed and position, the HCC strategy has been used to ensure that the actual motor phase currents tracked their respective sinusoidal references.

The HCC algorithm was developed and employed for the logical firing of the power semiconductor switches of the inverter. Optimization of the control algorithm yielded very fast speed response, under full load stress, with the motor attaining steady state at 0.01 seconds with minimal torque pulsation at steady state for the step and ramp reference speed inputs. Optimal control variables were identified with emphasis on effective current and torque tracking. The identified optimal control variables are: proportional gain $=5$, integral gain $=100$, first order low pass filter time constant $=1.6 \times 10^{-3}$ seconds, torque limiter upper/lower limits $=30 /-30 \mathrm{Nm}$, and hysteresis band $\Delta=0.05$. Effective tracking in current and torque was achieved confirming that the control variables are optimal for a wide range of the PMSM ratings. Drive performance with ramp reference speed input offered gradual speed transition from positive to negative maintaining positive speed profile compared to the step reference speed input which forced the torque reference to the negative limit at the instant of speed reversal thereby permitting operation in four quadrants.

Finally, compared to the standard AC6 of MATLAB Simpower systems, the developed model achieved rise time and settling time of 0.0108 and 0.0143 seconds respectively while the corresponding values for AC6 model are 0.1944 and 0.1984 seconds respectively. This, clearly, shows that the developed model has an enhanced speed response.

\section{Appendix 1: Inverter Switch Gating Voltage Signal Estimation}

(a) For inverter phase "a" leg

If $i_{1}<i_{a}^{*}-\Delta i_{q s}^{*}$ OR $\left(i_{1}>i_{a}^{*}-\Delta i_{q s}^{*}\right.$ AND $i_{1}<i_{a}^{*}+\Delta i_{q s}^{*}$ $\left.\operatorname{AND} \frac{\mathrm{d} i_{a}}{\mathrm{~d} t}>0\right)$

$v_{g 1}=1 ; v_{g 4}=0$

else $v_{g 1}=0 ; v_{g 4}=1$

end

(b) For inverter phase "b" leg

If $i_{b}<i_{b}^{*}-\Delta i_{q s}^{*}$ OR $\left(i_{b}>i_{b}^{*}-\Delta i_{q s}^{*}\right.$ AND $i_{b}<i_{b}^{*}+\Delta i_{q s}^{*}$

AND $\left.\frac{\mathrm{d} i_{b}}{\mathrm{~d} t}>0\right)$

$v_{g 3}=1 ; v_{g 6}=0$

else $v_{g 3}=0 ; v_{g 6}=1$

end (c) For inverter phase "c" leg

If $i_{c}<i_{c}^{*}-\Delta i_{q s}^{*}$ OR $\left(i_{c}>i_{c}^{*}-\Delta i_{q s}^{*}\right.$ AND $i_{c}<i_{c}^{*}+\Delta i_{q s}^{*}$ $\left.\operatorname{AND} \frac{\mathrm{d} i_{c}}{\mathrm{~d} t}>0\right)$

$v_{g 5}=1 ; v_{g 2}=0$

else $v_{g 5}=0 ; v_{g 2}=1$

end

\section{Appendix 2: PMSM Ratings}

\begin{tabular}{l|l}
\hline Rated torque, Speed and Power & $26 \mathrm{Nm}, 3000 \mathrm{rpm}$ and $11 \mathrm{Hp}$ \\
Stator Phase Resistance $R_{s}(\Omega)$ & 0.11 \\
Stator Quadrature & 0.00097 \\
Axis Inductance $L_{q}(\mathrm{H})$ & \\
Stator Direct & 0.00097 \\
Axis Inductance $L_{d}(\mathrm{H})$ & \\
Flux Linkage established & 0.1119 \\
by Magnet $(\mathrm{Wb})$ & 81.1857 \\
Voltage Constant $(\mathrm{Vph} / \mathrm{rpm})$ & 0.6714 \\
Torque Constant $(\mathrm{Nm} / \mathrm{A}-\mathrm{peak})$ & 0.0016 \\
Inertia Constant $\mathrm{J}\left(\mathrm{kg}-\mathrm{m}^{2}\right)$ & 0.0002024 \\
Viscous Frictional Constant B & 8 \\
Number of Poles &
\end{tabular}

\section{REFERENCES}

[1] PILLAY, P.-KRISHNAN, R.: Control Characteristics and Speed Controller Design for a High Performance Permanent Magnet Synchronous Motor Drive, IEEE Trans. on Power Electronics 5 No. 2 (Apr 1990), 151-159.

[2] INOUE, Y.-YAMADA, K. MORIMOTO,S.;SANADA,M.- : Effectiveness of Voltage Error Compensation and Parameter Identification for Model-Based Sensorless Control of IPMSM, IEEE Trans. on Industry Applications 45 No. 1 (Jan-Feb 2009, $213-221$.

[3] SAYEEF, S.-FOO, G.-RAHMAN, M. F. : Rotor Position and Speed Estimation of a Variable Structure Direct-Torque-Controlled IPM Synchronous Motor Drive at Very Low Speeds Including Standstill, IEEE Trans. on Industrial Electronics 57 No. 11 (Nov 2010), 3715-3723.

[4] FOO, G.-RAHMAN, M. : Sensorless Direct Torque and Flux-Controlled IPM Synchronous Motor Drive at Very Low Speed Without Signal Injection, IEEE Trans. on Industrial Electronics 57 No. 1 (Jan 2010), 395-403.

[5] INOUE, Y.-MORIMOTO, S.-SANADA, M. : Comparative Study of PMSM Drive Systems Based on Current Control and Direct Torque Control in Flux-Weakening Control Region, IEEE Trans. on Industry Applications 48 No. 6 (Nov-Dec 2012), 2382-2389.

[6] KSHIRSAGAR, P.-BURGOS, R.-JIHOON, J.-LIDOZZI, A.-FEI, W.-BOROYEVICH, D.-SEUNG-KI, S. : Implementation and Sensorless Vector-Control Design and Tuning Strategy for SMPM Machines in Fan-Type Applications, IEEE Trans. on Industry Applications 48 No. 6 (Nov-Dec 2012), 2402-2413.

[7] STOJAN, D.-DREVENSEK, D.-PLANTIC, Z.-GRCAR, B.-STUMBERGER, G.: Novel Field-Weakening Control Scheme for Permanent-Magnet Synchronous Machines Based 
on Voltage Angle Control, IEEE Transactions on Industry Applications 48 No. 6 (Nov-Dec 2012), 2390-2401.

[8] MARCIC, T.-STUMBERGER, B.-STUMBERGER, G.HADZISELIMOVIC, M.-VIRTIC, P.-DOLINAR, D. : LineStarting Three and Single Phase Interior Permanent Magnet Synchronous Motors: Direct Comparison to Induction Motors, IEEE Trans. on Magnetic 44 No. 11 (Nov 2008), 4413-4416.

[9] MARCIC, T.-STUMBERGER, B.-STUMBERGER, G. : Comparison of Induction Motor and Line-Start IPM Synchronous Motor Performance in a Variable-Speed Drive, IEEE Trans. on Industry Applications 48 No. 6 (Nov-Dec 2012), 2341-2352.

[10] STUMBERGER, B.-MARCIC, T.-HADZISELIMOVIC, M. : Direct Comparison of Induction Motor and Line-Start IPM Synchronous Motor Characteristics for Semi-Hermetic Compressor Drives, IEEE Trans. on Industry Applications 48 No. 6 (Nov-Dec 2012), 2310-2321.

[11] SEKERAK, P.-HRABOVCOVA, V.-PYRHÖNEN, J.-KALAMEN, L.-RAFAJDUS, P.-ONUFER, M.: Ferrites and Different Winding Types in Permanent Magnet Synchronous Motor, Journal of Electrical Engineering (Elektrotechnicky Casopis) 63 No. 3 (2012), 162-170.

[12] OBATA. M.-MORIMOTO, S.-SANADA, M.-INOUE, Y. : Performance of PMASynRM with Ferrite Magnets for EV/HEV Applications Considering Productivity, IEEE Trans. on Industry Applications 50 No. 4 (Dec 2013), 2427-2435.

[13] SANADA, M.-INOUE, Y.-MORIMOTO, S.: Structure and Characteristics of High-Performance PMASynRM with Ferrite Magnets, Electrical Engineering in Japan 187 No. 1 (2014), $42-50$.

[14] MORIMOTO, S.-OOI, S.-INOUE, Y.-SANADA, M. : Experimental Evaluation of a Rare-Earth-Free PMASynRM with Ferrite Magnets for Automotive Applications, IEEE Trans. on Industrial Electronics 61 No. 10 (Jan 2014), 5749-5756.

[15] UDDIN, M.-RADWAN, T.-GEORGE, G.-RAHMAN, M. : Performance of Current Controllers for VSI-Fed IPMSM Drive, IEEE Trans. on Industry Applications 36 No. 6 (Nov-Dec 2000), 1018-1025

[16] KAZMIERKOWSKI, M.-MALESANI, L. : Current Control Techniques for Three-Phase Voltage-Source PWM Converters: A Survey, IEEE Trans. on Industrial Electronics 45 No. 5 (Oct 1998), 691-703.

[17] RAHMAN, K.-KHAN, M.-CHOUDHURY, M.-RAHMAN, M.: Variable-Band Hysteresis Current Controllers for PWM Voltage-Source Inverters, IEEE Trans. on Power Electronics 12 No. 6 (Nov 1997), 964-970.

[18] HYUNG-TAE, M.-HYUN-S, K.-MYUNG-JOONG, Y.: A discrete-Time Predictive Current Control for PMSM, IEEE Trans. on Power Electronics 18 No. 1 (Jan 2003), 464-472.

[19] RODRIGUEZ, J.-PONTT, J.-SILVA, C. A.-CORREA, P.-LEZANA, P.-CORTES, P.-AMMANN, U.: Predictive Current Control of a Voltage Source Inverter, IEEE Trans. on Industrial Electronics 54 No. 1 (Feb 2007), 495-503.

[20] CORTES, P.-KAZMIERKOWSKI, M. P.-KENNEL, R. M. QUEVEDO, D.-RODRIGUEZ, J.: Predictive Control in Power Electronics and Drives, IEEE Trans on Industrial Electronics 55 No. 12 (Dec 2008), 4312-4324.

[21] KRAUSE, P. C. : Analysis of Electric Machinery, McGraw-Hill, New York, 1986.

[22] STUlRAJTER, M.-HRABOVCOVA, V.-FRANKO, M.: Permanent Magnets Synchronous Motor Control Theory, Journal of Electrical Engineering 58 No. 2 (2007), 79-84.
Received 6 January 2016

Cosmas Ogbuka (Engr Dr) was born in Umuna Nigeria on 1st April, 1981. He received his BEng (First Class Honors), MEng (Distinction) and $\mathrm{PhD}$ in 2004, 2009 and 2014 respectively in the Department of Electrical Engineering University of Nigeria, Nsukka, where he presently works as a Lecturer I. His research interests are in Adjustable Speed Drives of Electrical Machines: (DC and AC Electric Machine Torque/Speed Control with Converters and Inverters), Electric Machines and Power Electronics. He has published both locally and internationally and attended conferences within and outside Nigeria. He is a member of Nigerian Society of Engineers (NSE), Nigerian Institution of Electrical Engineers (NIEEE), International Association of Engineers (IAENG) and is registered by the Council for the Regulation of Engineering in Nigeria (COREN). He is presently on a postdoctoral research visit at the Chair of Electrical Drives and Actuators (EAA) Universität der Bundeswehr München, Germany with Professor Dr-Ing Dieter Gerling.

Cajethan Nwosu (Engr Dr) was born 1st October 1967. He obtained the BEng, MEng, and PhD Degrees in Electrical Engineering from the University of Nigeria, Nsukka in 1994, 2004, and 2015 respectively. In 2007, he undertook a three months pre-doctoral research on Wind/Solar Hybrid Power System and Renewable Energy Resources at the University of Technology, Delft (TU-Delft), the Netherlands. Since 2005, he has been with the Department of Electrical Engineering, University of Nigeria, Nsukka, where he is currently a Senior Lecturer. He had written two books and had published over thirty articles both in local and international journals. He is an executive member of Nigerian Institution of Electrical and Electronic Engineers (NIEEE), Nsukka chapter. He is a member of Power Electronics Society of Institution of Electrical and Electronic Engineering (PES IEEE). He is an editorial board member World Science Journal of Engineering Applications. His areas of research interest include power electronic converters, electrical drives and renewable energy technologies.

Marcel Agu (Engr Prof), born in 1947 in Ohebe-Dim Nigeria, obtained his BSc in Electrical Engineering in 1974 in the University of Nigeria, Nsukka. He also received his MASc and $\mathrm{PhD}$ in 1978 and 1982 respectively in Power Electronics from the University of Toronto Canada. He is a Professor of Power Electronic in the Department of Electrical Engineering University of Nigeria, Nsukka. His research interests are, but not limited to, Power Electronic Circuits [Solid State $\mathrm{AC} / \mathrm{DC}$ and DC/DC Converters, Inverter Circuits and Cycloconverter/inverter circuits ], Static Electric Motor Drives (DC and AC Electric Machine Torque/Speed Control with Converters and Inverters), Analogue, digital and microprocessorbased electronic control circuits, Static Induction Heating Power Supplies for heat treatment of metals (melting, casting, forging, forming, annealing, hardening), Renewable Energy Sources (especially in the area of working with solar photo voltaic cells and panels to realize solar lighting, heating, battery charging and water pumping), Power System Distribution for Residential, Commercial and Industrial Areas. He has published wide both in local and international journals. 